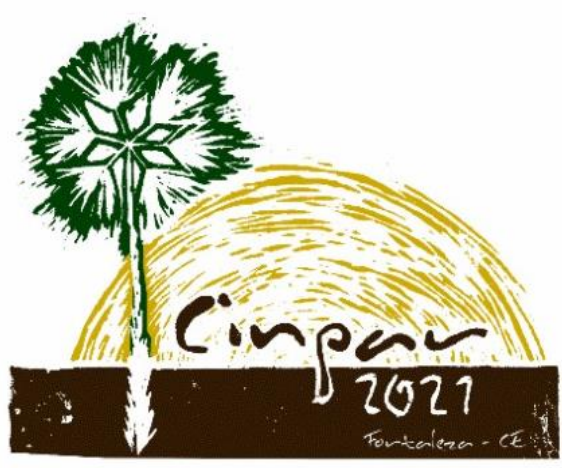

XVII Congresso Internacional sobre Patologia e

Reabilitação das Construções

XVII Congreso Internacional sobre Patología y Rehabilitación de las Construcciones

XVII International Conference on Pathology and Constructions Rehabilitation

FORTALEZA (Brasil), 3 a 5 de junho de 2021

https://doi.org/10.4322/CINPAR.2021.021

\title{
Manifestações patológicas em fundação de Obras de Arte Especiais: Estudo de Caso
}

\section{Pathologies in the foundation of bridges and viaducts: Case of Study}

\author{
Rodrigo Pereira ${ }^{1}$, Pedro H. Lucena ${ }^{2}$, Ana C. V. Salles ${ }^{3}$, Caroline P. Alves ${ }^{4}$, Giovana A. de Oliveira ${ }^{5}$ \\ ${ }^{1}$ PUC-MG, Belo Horizonte, Brasil, rodrigoestruturas@gmail.com \\ 2 UFMG, Belo Horizonte, Brasil, pedrohenri_que@outlook.com \\ ${ }^{3}$ UFMG, Belo Horizonte, Brasil, anasalles1304@gmail.com \\ ${ }^{4}$ UFMG, Belo Horizonte, Brasil, caroline.pedrosaalves@gmail.com \\ ${ }^{5}$ UFMG, Belo Horizonte, Brasil, abreu_giovana@hotmail.com
}

\begin{abstract}
Resumo: As Obras de Arte Especiais (OAEs) são consideradas de grande importância para o desenvolvimento da economia de um país, no que se refere ao escoamento de grãos e transporte público. A ausência de estudos hidrológicos, topográficos, geológicos e geotécnicos, muitas vezes desconsiderados pelos projetistas, acarreta durante a vida útil das estruturas degradações consideráveis, que podem levar ao seu colapso. O presente trabalho tem como objetivo apresentar as principais manifestações patológicas em fundação de OAEs e suas causas prováveis, como a erosão, ampliando o conhecimento ainda pouco estudado. As estacas são classificadas como elementos de fundação profunda (mais de 3,0 metros, segundo a NBR 6122), utilizadas para transmitir as cargas da edificação para o solo. Isso é feito de duas formas: pelas laterais da estaca (resistência de fuste) e pela ponta. No trabalho será apresentada uma sistemática das manifestações patológicas em fundações nas estacas presentes em duas OAEs situadas no estado do Maranhão e Pernambuco.
\end{abstract}

Palavras-chave: Obras de Arte Especiais; Fundação em estacas; Erosão; Manifestações patológicas.

Abstract: Bridges and viaducts are considered of great importance for the development of a country's economy, with regard to grain flow and public transport. The absence of hydrological, topographic, geological and geotechnical studies were often disregarded by the engineers, leading to considerable pathologies during their service life, which often led to the collapse of the structure. The present work aims to present the main founding pathologies in bridges and viaducts and their probable causes such as erosion, expanding the knowledge not yet studied. The piles are classified as deep foundation elements (more than 3,0m according to NBR 6122), used to transmit the building loads to the ground. This is done in two ways: from the around of the pile (shaft resistance) and from the end bearing pile. The work will present a systematic of the pathologies in foundations in the piles present in three bridges and viaducts from different regions of Brazil.

Keywords: Bridges and viaducts; foundation piles; erosion; pathology.

\section{Introdução}

Coduto et al. (2015) indicam a importância de uma base sólida e que a integridade de uma estrutura não pode ser maior que a de sua fundação. Se uma fundação falhar, a estrutura subjacente falha com ela. Além 
disso, destacam que as manifestações patológicas de fundações são mais difíceis de serem identificadas e reparadas após sua execução.

Apesar das dificuldades, há estudos que endereçam diversas manifestações patológicas à execução e projeto das fundações. Segundo Dal Molin (1988), 5,59\% das fissuras em estruturas de concreto são originadas por problemas na fundação. Análises feitos por Alves (2009) em edificios em Goiás concluiu que a maior parte dos danos emcontrados nos estudos de caso foram provocados por erros na fase de projeto e execução da fundação. Os estudos supracitados apresentam grandes evidências da necessidade de melhores projetos e definições normativas de elementos de fundação. No âmbito das Obras de Arte Especiais, ainda há grande carência de trabalhos que visam estimar estatisticamente e qualitativamente a relação entre manifestações patológicas comumente encontras durante inspeções rotineiras e possível erros em fundações, embora, como observado por Vitório e Barros (2012), esses elementos estruturais serem de grande relevância para a estrutura como um todo, pela peculiaridades e por estarem expostas a condições ambientais diversas.

Em especial, buscou-se, neste estudo, avaliar manifestações patológicas em estacas, pois é um dos tipos mais comuns de fundação em OAEs atualmente. A estaca é, segundo a NBR 6122 (ABNT, 2019), um elemento executado por equipamentos ou ferramentas sem que haja trabalho manual na sua profundidade, podendo ser classificada como fundação profunda. Esta classificação está relacionada à sua forma de transmissão de carga, que é realizada pela base (resistência de ponta) e/ou pela lateral (resistência de fuste); e pela sua dimensão, cujo comprimento deve ser 8 (oito) vezes superior a sua dimensão em planta, com um mínimo de 3,0 metros.

Conforme Milititsky et al. (2005), a execução de uma estaca pode variar de acordo com condicionantes de campo. A ocorrência de limitações do maquinário utilizado, além de variações do subsolo em relação à etapa de investigação geológica, exigem mudanças no projeto. Observa-se que este último representa grande parte da problemática em projetos de fundações.

Antes mesmo de se calcular os esforços solicitantes de uma estrutura que será construída, deve-se estudar as particularidades do solo. Quando o número de sondagens de reconhecimento é insuficiente, camadas com comportamentos distintos podem não ser identificadas, bem como sua distribuição no terreno e, muitas vezes, essas camadas também serão solicitadas pelo carregamento submetido à estrutura. É de grande importância a visita ao local da obra pelo engenheiro calculista, de forma a identificar feições topográficas; possíveis instabilidades de taludes; possível contaminação do solo por agentes externos; estado, porte e tipo de edificações vizinhas à obra, particularidades geológico-geotécnicos nas imediações, como afloramentos rochosos, áreas de brejo e a existência de minas d'água (ABNT, 2019).

Alguns problemas típicos devido a má investigação geotécnica são apresentados por Milititsky et al. (2005) para fundações profundas no Quadro 1 a seguir:

Quadro 1 -Problemas típicos observados o tipo de fundação profunda. Fonte: MILITITSKY et al., (2005), adaptado

\begin{tabular}{|l|l|}
\hline TIPO DE FUNDAÇÃO & \multicolumn{1}{|c|}{ PROBLEMAS TíPICOS DECORRENTES } \\
\hline \multirow{5}{*}{ Fundações profundas } & $\begin{array}{l}\text { Estacas de tipo inadequado ao subsolo, resultando mau } \\
\text { comportamento. }\end{array}$ \\
\cline { 2 - 2 } & $\begin{array}{l}\text { Geometria inadequada, comprimento ou diâmetros inferiores aos } \\
\text { necessários. }\end{array}$ \\
\cline { 2 - 2 } & $\begin{array}{l}\text { Estacas apoiadas em camadas resistentes sobre solos moles, com } \\
\text { recalques incompatíveis com a obra. }\end{array}$ \\
\cline { 2 - 2 } & $\begin{array}{l}\text { Ocorrência de atrito negativo não previsto, reduzindo a carga } \\
\text { admissível nominal adotada para a estaca. }\end{array}$ \\
\hline
\end{tabular}

Os problemas encontrados nas situações reais durante a etapa de execução podem ser intensificados à medida que não há o controle dos recalques admissíveis. Esta problemática envolve a definição de um estado de recalque em que a estrutura é comprometida e sua segurança não pode ser mais assegurada, para que sirva como parâmetro durante a obra. Apesar de complexo, há normas e estudos que definem valores para 
se ter uma ordem de grandeza. Abaixo, segue um diagrama (Figura 2) com base em estudos de Bozozuk (1978, apud MILITITSKY et al., 2005) para limites de deslocamentos verticais e horizontais de pontes.

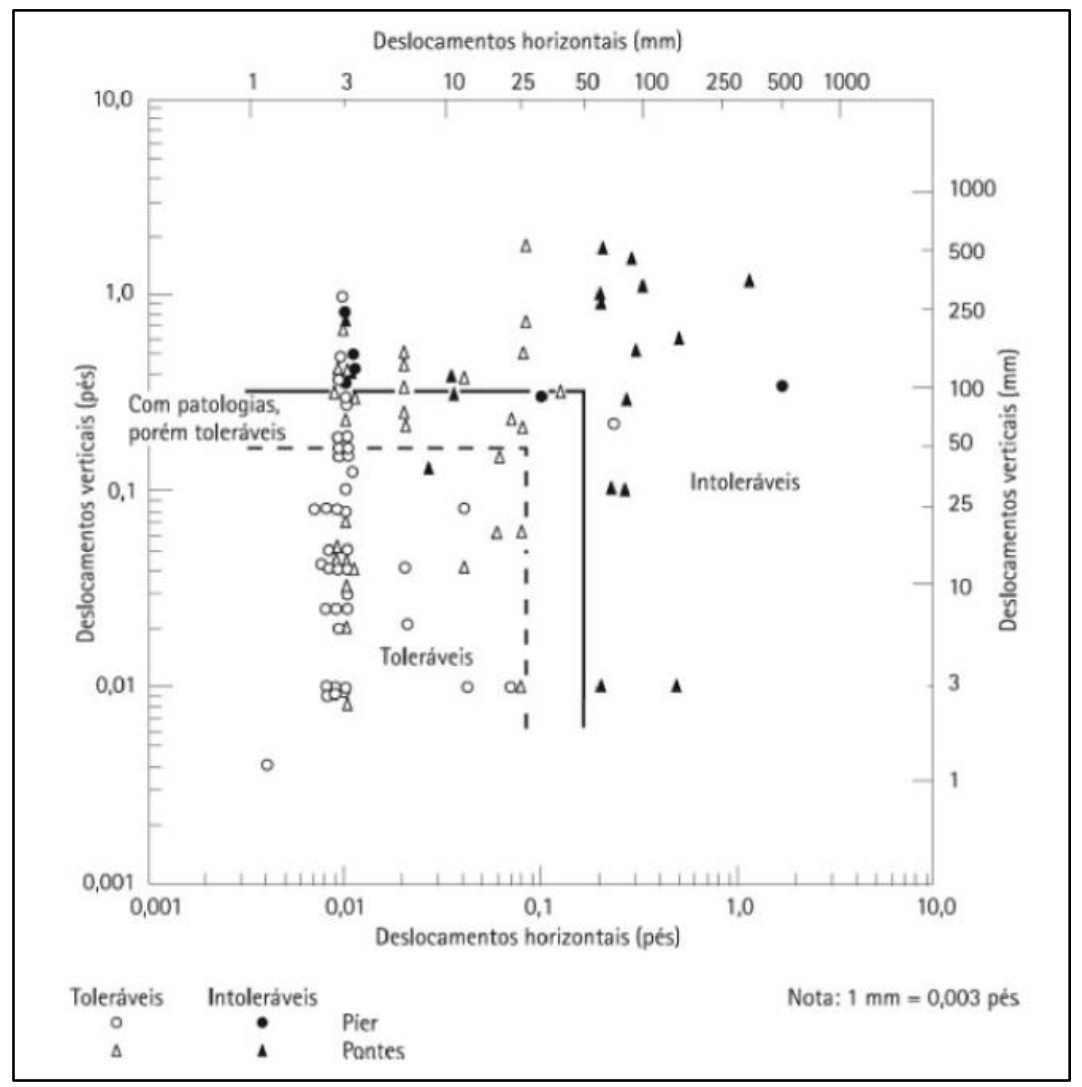

Figura 2 - Limites de deslocamentos verticais e horizontais de pontes. Fonte: BOZOZUK, 1978, apud MILITITSKY et al., 2005

Neste trabalho, buscou-se identificar obras que, por meio de inspeções Cadastrais Rotineiras, indicassem um estado precário de sua fundação, para que fosse possível realizar uma caracterização estrutural e situacional, de modo a apresentar as manifestações patológicas encontradas, bem como identificar os principais erros técnicos cometidos. Portanto, escolheu-se duas Obras de Arte Especiais de grande importância para a região em que estão localizadas, bem como obras que estão expostas a ambientes agressivos.

\section{Definições Normativas}

As causas frequentes de manifestações patológicas em fundações estão intrinsecamente ligadas à fase de projeto e execução das mesmas. Observa-se que problemas envolvendo o comportamento do solo são derivados de erros na interpretação de investigações geológicas, ou ainda, de falhas resultantes de um número insulficiente de sondagens e a não previsão da existência de matacões ou de aterros assimétricos. $\mathrm{A}$ fim de se evitar isto, a norma NBR 6484 (ABNT, 2001) estipula que, antes da profundidade estimada para o projeto, devem ser realizadas mais quatro sondagens a percussão, deslocadas a 2,0 metros de distância da sondagem inicial, em direções opostas. Ainda, em caso de dúvidas, a norma 6122 (ABNT, 2019) especifica a utilização de sondagens mistas (percussão e rotativas). No entanto, deve-se ter em mente que essas Normas fornecem somente critérios mínimos, podendo ser necessárias mudanças conforme o tipo de obra, características e composição do solo.

Outro fator preponderante no tocante às manifestações patológicas de estruturas, é quanto à agressividade do ambiente onde a obra está inserida. No caso de fundações, a agressividade do solo e da água (ambos, quando se trata de pontes) devem ser levados em conta e deve-se tomar as devidas considerações ao longo da fase de projeto. Neste âmbito, a Norma Técnica NBR 6118 (ABNT, 2014) define uma relação entre a classe de agressividade do ambiente (Quadro 2) e parâmetros mínimos para a conservação e boa trabalhabilidade 
do concreto ao longo da sua vida útil, indicando recomendações como espessura de cobrimento das armaduras (Quadro 3) e a classe de resistência mecânica do concreto para cada classe.

Quadro 2 - Classes de agressividade ambiental (CAA). Fonte: NBR 6118 (ABNT, 2014), adaptado

\begin{tabular}{|c|c|c|c|}
\hline $\begin{array}{c}\text { Classe de } \\
\text { agressividade } \\
\text { ambiental }\end{array}$ & Agressividade & $\begin{array}{c}\text { Classificação do } \\
\text { tipo de ambiente }\end{array}$ & $\begin{array}{l}\text { Deterioração da } \\
\text { estrutura }\end{array}$ \\
\hline I & Fraca & $\begin{array}{c}\text { Rural } \\
\text { Submersa }\end{array}$ & Insignificante \\
\hline II & Moderada & Urbana & Pequeno \\
\hline III & Forte & Industrial & Grande \\
\hline IV & Muito Forte & Respingos de Maré & Elevado \\
\hline
\end{tabular}

Quadro 3 - Correspondência entre CAA e cobrimento nominal.Fonte: NBR 6118 (ABNT, 2014), adaptado

\begin{tabular}{|c|c|c|c|c|c|}
\hline \multirow{2}{*}{$\begin{array}{c}\text { TIPO DE } \\
\text { ESTRUTURA }\end{array}$} & \multirow{2}{*}{$\begin{array}{c}\text { Componente ou } \\
\text { elemento }\end{array}$} & \multicolumn{4}{|c|}{ Classe de agressividade ambiental } \\
\cline { 3 - 6 } & Laje & 20 & 25 & 35 & 45 \\
\hline \multirow{3}{*}{\begin{tabular}{c} 
Concreto Armado \\
\cline { 2 - 6 }
\end{tabular}} & Viga/pilar & 25 & 30 & 40 & 50 \\
\cline { 2 - 6 } & $\begin{array}{c}\text { Elementos em contato } \\
\text { com solo }\end{array}$ & \multicolumn{2}{|c|}{30} & 40 & 50 \\
\hline $\begin{array}{c}\text { Concreto } \\
\text { Protendido }\end{array}$ & Laje & 25 & 30 & 40 & 50 \\
\cline { 2 - 6 } & Viga/Pilar & 30 & 35 & 45 & 55 \\
\hline
\end{tabular}

Porém, como mostra Albuqerque e Otoch (2005), algumas regiões apresentam peculiaridades que não são contemplatadas pela norma. Por isto, se vê necessário o desenvolvimento de uma classificação específica, que no caso dos autores, foi feita para a cidade de Fortaleza, no Ceará. Isto devido à forte salinidade do mar e dos ventos alísios, que propagam as gotículas de água ao longo da cidade (LEAL; PAMPLONA, 1982, apud ALBUQERQUE; OTOCH, 2005).

\section{Manifestações patológicas}

3.1 Manifestações patológicas ocasionadas pelas interações entre o solo e elementos de fundações

A análise das interações solo-estrutura é essencial para a entender a ocorrência de manifestações patológicas que afetam as fundações. Dentre elas, é possível citar: efeito Tschebotarioff, efeito do atrito negativo, efeito de sobreposição de estacas próximas, etc.

O efeito Tschebotarioff ocorre quando há sobrecarga próximo às estacas cravadas através de uma camada de argila mole, sem a ocorrência de deslocamento de material, em que são produzidos deslocamentos horizontais e adensamento, gerando solicitações nas estacas (TSCHEBOTARIOFF, 1962 Apud PIRES, 2013). Segundo Souza (2003), quanto maior a plasticidade do solo submetido ao carregamento, maiores serão as tensões verticais e horizontais, bem como seus respectivos deslocamentos, contribuindo com a flexão das estacas de fundação. Isto acaba refletindo no comportamento de outros elementos da estrutura, como pilares e encontros. Aoki (1970, apud PIRES, 2013) relata o surgimento de dasaprumos e fissuras em vários pilares devido ao rompimento da camada de argila mole após a execução de serviços de terraplanagem próximo a uma ponte localizada na BR-101, no Rio Grande do Norte. Alguns pilares chegaram a se deslocar 20 centímetros. 


\subsection{Degradações devido à agressividade do ambiente}

Como indicado por Battagin (2019, Apud PONTES, 2019), ao se conhecer a agressividade do ambiente, manifestações patológicas podem ser evitadas aumentando-se a durabilidade da estrutura com o uso de:

$>$ Concretos menos permeáveis;

$>$ Relação água $x$ cimento reduzido;

$>$ Cimentos de alto-forno;

$>$ Pozolânicos ou resistentes aos sulfatos.

Quando inseridas em águas com concentração acima de $150 \mathrm{mg} / \mathrm{l}$ de sólidos dissolvidos, já pode ser considerado agressiva ao concreto (GARCIA, 1999). Observa-se no concreto perda progressiva de massa e de resistência. A velocidade de degradação do concreto pode ser ainda mais acelerada quando uma das faces do elemento permite evaporação, enquando a outra permanece em contato com a água ou solo contaminado. Aliado à degradação do concreto, a corrosão da armadura é observada frequentemente. A corrosão do aço no concreto é uma reação eletroquímica, influenciada por vários fatores, como: nível de pH, permeabilidade do concreto e a concentração de íons cloreto. Para que a corrosão inicie, a camada passiva do aço deve estar destruída, de forma que haja contato entre os íons cloreto e o mesmo. O processo de corrosão é observado recorrentemente em estruturas que estão em contato com água do mar ou gotículas de água do mar transportadas por vento. (BALL; WHITMORE, 2005, apud MILITITSKY et al., 2005).

Em estacas metálicas, a norma NBR 6122 (ABNT, 2019) define que para estacas total e permanentemente enterradas, deve-se contabilizar uma espessura de compensação de corrosão, de forma que não sejam necessários tratamentos especiais de proteção das estacas. A espessura para os solos indicados estão dispostos no Quadro 4

Quadro 4 - Corrosão em estacas metálicas segundo a NBR 6122 (ABNT, 2019).

\begin{tabular}{|c|c|}
\hline Classe & Espessura mínima de sacrifício \\
\hline Solos em estado natural e aterros controlados & 1,0 \\
\hline Argila orgânica; solos porosos não saturados & 1,5 \\
\hline Turfa & 3,0 \\
\hline Aterros não controlados & 2,0 \\
\hline Solos contaminados ${ }^{\text {a }}$ & 3,2 \\
\hline a Casos de solos agressivos devem ser estudados especificamente \\
\hline
\end{tabular}

A natureza do meio corrosivo cuja estaca está em contato possui grande relevância no processo corrosivo das estruturas metálicas.

\subsection{Erosão}

O processo erosivo é comumente classificado entre erosão geral e erosão localizada. A primeira é caracterizada por independer da existência ou não da estrutura e sim de regime de cheias, confluências de rios ou por ações antrópicas, como construção de barragens. Já a segunda, a erosão se dá em locais específicos, como em torno de pilares e encontros de pontes e são causadas por estreitamento da seção do corpo d'água ou alterações do escoamento. Vale ressaltar que ambos os tipos de erosão podem ocorrer de forma simultânea, e que devem ser levados em conta pelo engenheiro responsável pelo projeto (SILVA, 2008).

Em pontes com apoios inseridos dentro da calha do rio, há o surgimento de uma zona de pressão causada pelo bloqueio do escoamento pela estrutura, gerando uma separação tridimensional do fluxo. O campo de pressão produz vórtices em direção ao interior da calha. Nas lateriais do apoio, há a formação de outros vórtices em formato de "ferradura", devido ao fluxo não afetado (ETTEMA et al., 2006). A Figura 3 ilustra os vórtices criados nos pilares de pontes que geram a erosão localizada desses elementos. 


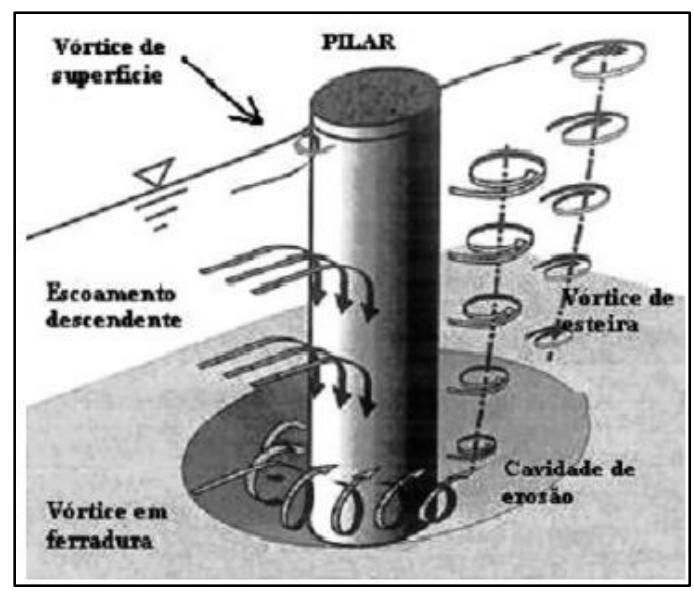

Figura 3 - Vórtices criados em torno dos pilares de pontes (CARDOSO, 2008, apud VITÓRIO, 2015)

Segundo Vitório (2015), a erosão localizada é influenciada por fatores como a intensidade do escoamento, bem como a direção do fluxo; altura da lamina d'água; dimensões dos sedimentos pertencentes ao leito do rio; grau de uniformidade dos sedimentos; geometria dos pilares; ângulo entre o fluxo de água e os pilares; fundações mal projetadas e/ou executadas, cuja profundidade é insuficiente; entre outros. Ainda segundo o autor, a forma do pilar merece a devida atenção por estar intrinsecamente ligado à profundidade de erosão e ao tipo de obstrução que esse elemento representa ao fluxo d'água.

\section{Estudos de caso}

A ponte sobre o Rio Jaboatão (lat. S $8^{\circ} 13^{\prime} 42,42^{\prime \prime}$, long. $\mathrm{O} 34^{\circ} 58^{\prime} 17,88^{\prime \prime}$ ) está situada no estado do Pernambuco, na BR-101, próxima à cidade de Cabo de Santo Agostinho, região metropolitana de Recife. A obra possui 2 vãos de 6,65 m, 2 vãos de 20,28 m, 2 vãos de 20,04 m e 1 vão de 20,06 m, totalizando 114,00 $\mathrm{m}$ de comprimento, com uma largura de $9,20 \mathrm{~m}$. Sua infraestrutura é formada por: estaca de concreto armado com camisa metálica e bloco de coroamento de concreto armado.

Na Figura 4, observa-se o revestimento metálico com forte corrosão, expondo o concreto, que por sua vez apresenta desagregação com oxidação da armadura. Segundo Vitório (2003), a oxidação da armadura, do qual se pode derivar a desagregação do concreto, podem ser causados por fatores como: deficiência no cobrimento da armadura, permeabilidade/porosidade do concreto e a existência de trincas. Fatores como agressividade do ambiente podem influenciar diretamente no surgimento dos danos encontrados.

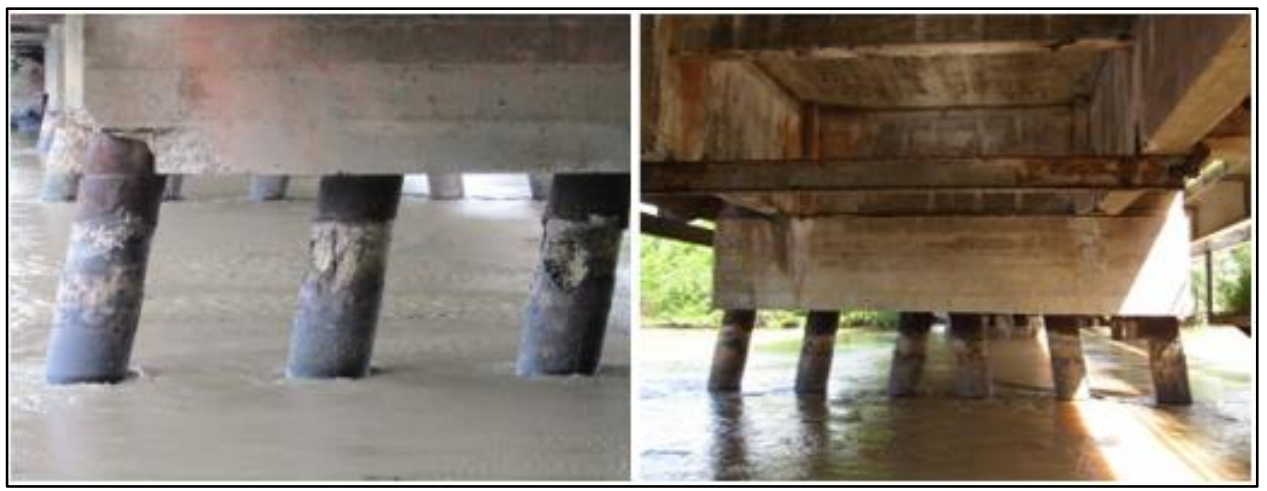

Figura 4 - Estacas com concreto desagregado, armadura oxidada e camisa metálica com corrosão

A ponte sobre o Rio Jaboatão localiza-se em uma região de meio ambiente agressivo classe II segundo a NBR 6118 (ABNT, 2014), em local com presença de indústrias de grande porte, áreas densamente urbanizadas e por ser o intertício entre a água salgada e a água doce. Segundo Moreira (2007), das indústrias localizadas na bacia hidrográfica do Rio Jaboatão, $75 \%$ delas geram efluentes sanitários e $25 \%$ geram efluentes industriais e sanitários, mas somente $8 \%$ delas possuem sistema de tratamento específico dos efluentes gerados. Outra fonte poluidora que impacta as águas do rio é o despejo de líquidos urbanos, oriundos dos municípios de Jaboatão dos Guararapes, Recife e Moreno. Gases como amônia $\left(\mathrm{NH}_{3}\right)$ e dióxido de carbono $\left(\mathrm{CO}_{2}\right)$, 
provenientes da decomposição de matéria orgânica nos efluentes lançados, podem originar manifestações patológicas no concreto como a carbonatação, provocada pelo dióxido de carbono, lixiviação e ataque ácido, provocados pela amônia (DIAS, 2018). Em uma das estações de monitoramento existentes ao longo da bacia do Rio Jaboatão, o valor máximo encontrado para a concentração de cloreto foi de $227 \mathrm{mg} / \mathrm{L}$ (MOREIRA, 2007). $O$ ataque por cloretos provoca danos sérios à armadura e não há um valor crítico de concentração de cloretos presentes no ambiente em que a estrutura está inserida (DIAS, 2018). A Norma NBR 6118 (ABNT, 2014) determina somente o teor de cloreto em relação à massa de cimento, não podendo ultrapassar o valor de $0,15 \%$.

A ponte sobre o Rio Cocal (lat. S $2^{\circ} 51^{\prime} 13,98^{\prime \prime}$ e long. $O 42^{\circ} 57^{\prime} 5,22^{\prime \prime}$ ) está situada no estado do Maranhão, na BR-402, próxima à cidade de Barreirinhas, há pouco mais de $24 \mathrm{~km}$ do litoral. A obra possui 2 vãos de $25,00 \mathrm{~m}$, com um comprimento total de 50,00 m e largura de 9,20 m. Sua infraestrutura é formada por: estacas metálicas tipo trilho de ferro e sapatas de concreto armado.

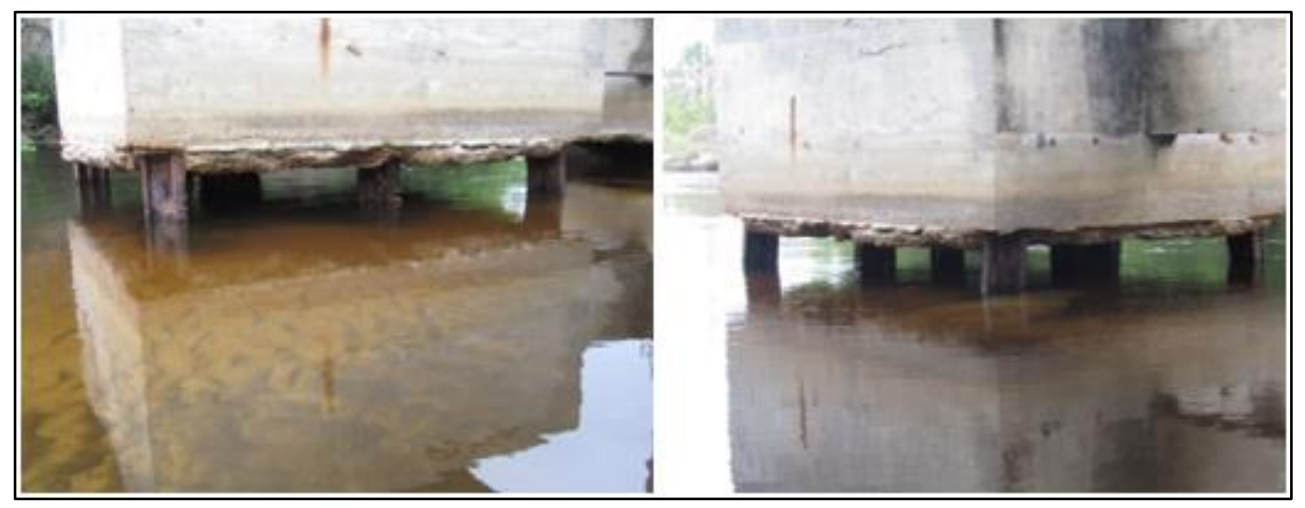

Figura 5 - Estacas com grau elevado de corrosão

Na Figura 5, é observado estacas com grau elevado de corrosão. Tanto o contato com a água quanto a possível existência de um solo corrosivo, pode provocar a inicialização do processo de corrosão das estacas. A corrosão das estacas resulta na redução da área da seção transversal do elemento e, consequentemente, reduz a capacidade de carga do elemento estrutural (POURSAEE et al., 2019). Segundo Decker (2008, apud POUSAEE et al., 2019), 25\% de perda de seção transversal são consideradas sérias. É possível observar também erosão da fundação devido ao rebaixamento do leito do rio, provocando o desconfinamento e exposição das estacas.

\section{Conclusões}

Nas obras avaliadas, observou-se que classificações pouco conservadoras em relação ao grau de agressividade do ambiente podem acarretar a especificação de espessura de cobrimento utilizados na fundação, incompatíveis com a realidade em que se encontram, podendo afetar a durabilidade e segurança da obra. No presente trabalho foram apresentadas as principais manifestações patológicas em fundações de OAEs, indicando que grandes partes delas podem ser evitadas ainda na fase projeto e na fase da execução, com investigações geotécnicas, geológicas, cartografica e hidrológicas mais acuradas.

\section{Referências Bibliográficas}

Albuqerque, A. T.; Otoch, S. (2005). Proposta de classificação da agressividade do ambiente na cidade de fortaleza. In: CONGRESSO BRASILEIRO DO CONCRETO, 47., 2005, Olinda. [Anais]. Olinda: IBRACON, 2005.

ALVES, J. R. (2009) Levantamento das Manifestações Patológicas em Fundações e Estruturas nas Edificações, com Até dez Anos de Idade, Executadas no Estado de Goiás. Dissertação de Mestrado (Curso de Mestrado em Engenharia Civil da EEC/UFG) - UFG, Goiânia, 2009.

Associação Brasileira De Normas Técnicas. (2001). ABNT NBR 6484: Solo - Sondagens de simples reconhecimento com SPT - Método de ensaio. Rio de Janeiro: ABNT, 2001. 
Associação Brasileira De Normas Técnicas. (2014). ABNT NBR 6118: Projeto de estruturas de concreto Procedimento. Rio de Janeiro: ABNT, 2014.

Associação Brasileira De Normas Técnicas. (2019). ABNT NBR 6122: Projeto e execução de fundações. Rio de Janeiro: ABNT, 2019.

Coduto, D. P. et al. (2015). Foundation Design: Principles and Practices. 3. Ed. Pomona: Prentice Hall, 2015.

DAL MOLIN, D. C. C. Fissuras em concreto Armado: Análise das Manifestações Típicas e Levantamento de Casos Ocorridos no Estado do Rio Grande do Sul. 1988. Dissertação de Mestrado (Curso de Pós-Graduação em engenharia Civil) - UFRGS, Porto Alegre, 1988.

Dias, N. G. (2018). Avaliação da deterioração das estruturas de concreto de estações de tratamento de esgoto. 2018. Dissertação (Mestrado em Engenharia Civil - Geotecnia, Estruturas e Construção Civil) Universidade Federal de Goiás, Goiânia, 2018.

Ettema, R.; Nakato, .T; Muste, M. (2006). An Illustrated Guide for Monitoring and Protecting Bridge Waterways against Scour. Ames: lowa Highway Research Board, 2006.

Faria, P. O.; Noronha, M. (2013). Fundações de Torres Eólicas - Estudo de Caso. In: SIMPÓSIO DE PRÁTICA DE ENGENHARIA GEOTÉCNICA DA REGIÃO SUL, 9., 2013, Criciúma. [Anais]. Criciúma: Geosul, 2013. p. 1-13.

Garcia, C. C. Incidências patológicas no subsistema estrutura de edifícios habitacionais na região de São Carlos/SP. Dissertação (Mestrado em Engenharia de Materiais) - Universidade de São Paulo, São Carlos, 1999.

Milititsky, J.; Consoli, N. C.; Schnaid, F. (2005). Patologia das Fundações. São Paulo: Oficina de Textos, 2005.

Moreira, H. A. (2007). Diagnóstico da qualidade ambiental da Bacia do Rio Jaboatão: sugestão de enquadramento preliminar. 2007. Dissertação (Mestrado em Engenharia Civil) - Universidade Federal de Pernambuco, Recife, 2007.

Pires, F. E. C. (2013). Empuxo de Sobrecargas Assimétricas em Estacas: Estudo de Casos de Pontes. Dissertação (Mestrado em Engenharia Civil) - Universidade Federal do Rio de Janeiro, Programa de Engenharia Civil, Rio de Janeiro, 2013.

Pontes, V. C. P. (2019). Efeitos dos sulfatos na degradação do concreto. Trabalho de conclusão de curso (Bacharelado em Engenharia Civil) - Universidade Federal da Paraíba, João Pessoa, 2019.

Poursaee, A.; Rangaraju, P.; Ding, L. (2019). Evaluation of H-pile Corrosion Rates for WI Bridges Located in Aggressive Subsurface Environments. Madison: Wisconsin Department of Transportation, 2019.

Silva, R. P. (2008) Estudo da erosão de pilares de pontes. 2008. Dissertação (Mestrado em Engenharia Civil Especialização em Hidráulica, Recursos Hídricos e Ambiente) - Universidade do Porto, Porto, 2008.

Souza, E. G. (2003). Colapso de edifício por ruptura das estacas: estudo das causas e da recuperação. São Carlos. 115 p. Dissertação (Mestrado em Engenharia Civil) - Escola de Engenharia de São Carlos, Universidade de São Paulo, 2003.

Vitório, J. A. P. (2003). Fundamentos da patologia das estruturas nas perícias de engenharia. Recife: Instituto Pernambucano de Avaliações e Perícias de Engenharia, 2003.

Vitório, J. A. P. (2014). Reforço de fundações de pontes e viadutos rodoviários. In: SEMINÁRIO PERNAMBUCANO DE ESTRUTURAS DE FUNDAÇÕES, 3., 2014, Recife. [Anais]. Recife: IBRACON, 2014.

Vitório, J. A. P. (2015). Fundamentos da erosão nas fundações de pontes e nos aterros de acesso. Recife, 2015. Apostila do Curso de Pós-Graduação em Engenharia da Universidade Federal de Pernambuco.

VITÓRIO, J. A. P., BARROS, R.M.M.C (2012). Reforço de Fundações de Pontes e Viadutos -Três Casos Reais-Anais do V Congresso Brasileiro de Pontes e Estruturas, Rio de Janeiro, 2012. 